\title{
Intensive long-term pulmonary rehabilitation program after oesophagectomy, a reflection
}

\author{
Franco Pasqua*
}

There is body of evidence regarding the efficacy of Pulmonary Rehabilitation (PR) in the comprehensive management of patients with respiratory disease, and PR programs are practiced worldwide. Positive results in terms of improvement in dyspnoea, exercise capacity and Quality of Life (QoL) are recognized in Chronic Obstructive Pulmonary Disease (COPD). However PR is beneficial in other forms of chronic respiratory diseases, like asthma, cystic fibrosis, restrictive thoracic disease etc. Moreover, PR is becoming a crucial component of the overall treating strategy in high risk surgical patients (i.e. lung volume reduction surgery [LVRS] and lung transplantation), and in the pre- and post-operative period of patients who are candidates or have undergone lung resection (LR) for Non-Small Cell Lung Cancer (NSCLC).

Pulmonary function is commonly altered after surgery, particularly in patients with COPD, current o ex smokers, who have had chest or upper abdominal surgery. The physiological changes observed are directly related to anesthesia (general or regional) and to the type of incision and surgical technique employed, and are reflected by decreases in total pulmonary capacity and pulmonary volumes and by a parallel reduction of $\mathrm{PaO}_{2}$. These functional alterations are in turn implicated in the development of postoperative pulmonary complications (PPC), which are the main causes of morbidity and mortality among surgical patients.

Therefore, the recovery of a good physical and respiratory function, the improvement of dyspnoea and quality of life are an important outcome in the postoperative management of these patients. Breathing exercises have commonly been used to increase pulmonary volumes and improve gas exchange and ventilation distribution. Diaphragmatic, segmental, and costal respiratory exercises, as well as sustained maximal inspiration, may alleviate surgically induced alterations such as

Correspondence: franco_pasqua@fastwebnet.it

Department of Pulmonary Rehabilitation "IRCCS San Raffaele", Rome, Italy diminished diaphragmatic mobility and restrictive pulmonary changes.

On the other hand a comprehensive program of pulmonary rehabilitation is able to improve dyspnoea, exercise capacity and quality of life of surgical patients, and it is now known that a better preoperative fitness is inversely related to postoperative complications. Also, the functional recovery in surgical patients is faster and complications are reduced after pulmonary rehabilitation.

Surgery for oesophageal cancer is a serious life-event, which may be accompanied by significant morbidity that may influence the patient's quality of life. Common postoperative symptoms include dysphagia, weight loss and change in eating patterns. In addition, these patients experience, particularly in the first year after oesophageal resection, pain, fatigue, dyspnoea, depression and impaired quality of life, symptoms that are associated with increased risk of shorter survival. Among various postoperative complications after oesophagectomy, the pulmonary ones occur in approximately $30 \%$ of cases and they are major causes of postoperative morbidity and mortality $[1,2]$.

Despite these considerations, little evidence is currently available on the effectiveness of a comprehensive program of pulmonary rehabilitation on these symptoms, particularly the QoL, in subjects who have undergone surgery for oesophageal cancer [3].

The paper "Rationale and clinical benefits of an intensive long-term pulmonary rehabilitation program after oesophagectomy: preliminary report", by Lococo and collegues, published in this journal, is interesting because it is, to our knowledge, the first devoted to this particular issue [4].

The authors retrospectively analyzed data from two groups of patients with a recent surgery for esophageal cancer, who underwent a standard rehabilitation therapy (control group) or a four weeks outpatient comprehensive program of pulmonary rehabilitation (treated group). 
The results show a significant improvement in lung function (Total Lung Capacity, Forced Expiratory Volume and Forced Vital Capacity), in the treated group compared to the control group.

Similar improvements were found in terms of six minute walking distance (6MWD), dyspnoea, measured with the Visual Analog Scale (VAS) and Borg Scale, and Bartel Disability Index.

Considering that the deterioration of postoperative lung function is associated with a worse quality of life, the authors hypothesized that an improvement in lung function and exercise capacity may improve this outcome.

We think that the idea for the study is very interesting, but the methods and results are not clear. First, it is not acceptable that the authors did not use any questionnaire or investigations to measure QoL, while they did stress several times its role in patients who underwent oesophagectomy for cancer. Then, they do not clearly describe the rehabilitation protocol used in treated group; and finally the study was conducted retrospectively.

In our opinion, further prospectively planned studies would be necessary to investigate the effectiveness of pulmonary rehabilitation not only after, but also before the surgery, because pre-operative training programs may led to a reduction of hospital stay and postoperative complications.

Received: 11 July 2012 Accepted: 11 July 2012

Published: 30 July 2012

\section{References}

1. Rutegård M, Lagergren P, Rouvelas I, Mason R, Lagergren J: Surgical complications and long-term survival after esophagectomy for cancer in a nationwide Swedish cohort study. Eur I Surg Oncol 2012, Epub ahead of print.

2. Kinugasa S, Tachibana M, Yoshimura H, Ueda S, Fujii T, Dhar DK, Nakamoto $\mathrm{T}$, Nagasue N: Postoperative pulmonary complications are associated with worse short- and long-term outcomes after extended esophagectomy. J Surg Oncol 2004, 88:71-77.

3. Dettling DS, van der Schaaf M, Blom RL, Nollet F, Busch OR, van Berge Henegouwen MI: Feasibility and Effectiveness of Pre-operative Inspiratory Muscle Training in Patients Undergoing Oesophagectomy: A Pilot Study. Physiother Res Int 2012, doi:10.1002/pri.1524.

4. Lococo F, Cesario A, Sterzi S, Magrone G, Dall'Armi V, Mattei F, Varone F, Porziella V, Margaritora S, Granone P: Rationale and clinical benefits of an intensive long-term pulmonary rehabilitation program after oesophagectomy: preliminary report. Multidiscip Resp Med 2012, 7. in press.

doi:10.1186/2049-6958-7-22

Cite this article as: Pasqua: Intensive long-term pulmonary rehabilitation program after oesophagectomy, a reflection. Multidisciplinary Respiratory Medicine 2012 7:22.

\section{Submit your next manuscript to BioMed Central and take full advantage of:}

- Convenient online submission

- Thorough peer review

- No space constraints or color figure charges

- Immediate publication on acceptance

- Inclusion in PubMed, CAS, Scopus and Google Scholar

- Research which is freely available for redistribution 